[The reporter would add to the preceding explanation, his conviction that Dr. Bartlett has altogether-he is almost tempted to say, wilfully-misconceived Dr. Holmes's remarks. They were intended and understood to apply solely to the position in which Dr. B. as a professional man, stood in relation to the Association-and not in the slightest degree to his private personal character. This is evident from the connection in which the objectionable sentence appears, and must have struck Dr. B. at once, had he not been inclined to misconstrue what is so perfectly plain.

So far as the reporter is concerned, there was no intention to warp the words of any man into an equivocal meaning to Dr. B.'s disadvantage. All the proceedings in this very unpleasant affair have been grounded upon professional acts and misdemeanors, and as yet there has been no disposition (on one side, at least) to extend the inquiry into private character and habits. Whether Dr. B. is in this respect, viz. abstinence from connecting irrelevant matters with the controversy, as clear as his opponents, is readily determined by reference to his published speeches. If he should be at a loss for an instance, I would remind him of the printed trial he exhibited to the Association, and upon which he founded an attack upon as honest and honorable a man as can be found in the ranks of the profession.

The reporter once more disclaims any desire of bringing Dr. Bartlett's private character into discussion, and, if necessary, will admit him to be,

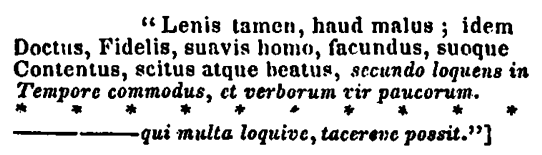

\title{
GRAHAMISM NOT A CAUSE OF INSANITY.
}

(Concluded from page 271.)

LET all the cases of insanity that Dr. Lee can bring forward, with the help of all those whom he calls upon, be fully given in every particular, of parentage, life, habits, circumstances, employment, events, \&c., and if I cannot show to the satisfaction of every candid and intelligent individual, that the "Graham System" is wholly free from any blame in each and every case, then let that system and its humble advocate stand convicted before the world, of all their errors, and receive all the censure they deserve. I do not fear to have my reputation, for the present and for the future, rest on the issue.

But, granting that a sudden change from a free use of animal food, tea, coffee, \&c. to a diet of pure vegetable food and water, might, during the temporary physiological depression which follows the change, serve to develope insanity in those who are strongly predisposed to it, - -would this fact prove that a well-regulated diet of pure vegetable food and water, is not best adapted to sustain the highest and best condition of human nature in all respects? Certainly not. It might with as much 
propriety be urged that, because delirium tremens sometimes follows the abandonment of intoxicating liquors, therefore the habitual use of such liquors is essential to the mental sanity of mankind; and water alone, as a drink, is not adapted to sustain the highest and best condition of human nature. The liability of some spirit drinkers to delirium tremens, from a sudden abandonment of intoxicating liquors, is a good reason why such individuals shosld regulate their change with discretion and propriety, but no reason whatever why they should continue to drink intoxicating liquors. So also, if the sudden abandonment of animal food would render some individuals liable to insanity, it would be a good reason why they should regulate their change judiciously - but no reason why they and all mankind should continue to eat animal food.

When the Temperance reform was first commenced, the unanimous opinion of the medical profession was, that men habituated to the free use of spirits could not suddenly be brought to total abstinence, without irnminent hazard of their lives. But without stopping to consult physicians, the reformers pushed forward their enterprise, and demonstrated, on a large scale, what physicians would never have believed without such a demonstration : and yet with this full demonstration before them, we find many-perhaps most of them, still contending that old men who have been in the habit of using intoxicating liquors, cannot safely abandon that habit. A more fallacious and fatal opinion cannot be clerished. But, let an error get once deeply rooted in medical opinion, and it is next to imposisible to extirpate it. It ought not, therefore, to be considered surprising that so many physicians are ready to raise the cry of alarm against the doctrines which I teach.

Dr. Lee asserts, that, "without one exception, all whom he has known to subsist on a purely vegetable ditt, gave evidence of bodily or mental imbecility, or both."

Surely the Dr. must have been peculiarly unfortunate in his acquaintance with vegetable eaters. Yet be cannot be ignorant that throughout all Europe, Asia and Africa, the laboring men who are the most remarkable for their physical powers and for their ability to endure protracted labor and fatigue, have been reared, and subsist entirely on vegetable food. "The case of the far-famed Caspar Hauser," adds the Dr., " is in point. Here was great delicacy and sensitiveness-keen susceptibility and feeling, with weakness of body and mind."

This is a very incorrect statement. For the strongest possible reason, Caspar Hauser was delicate and weak in body. He had all his life time been confined to his dark dungeon in a sitting posture-without any exercise. He came into the world a perfect infant of seventeen years old -in body and mind be was infantile, except in the size of his body-he had intellectual faculties, but he had scarcely any mind ;- but to say that his intellectual powers were weak, is to contradict the direct testimony of his biographer and the strongest and most ample evidence of fact. The truth is, Dr. Lee confounds a want of mental cultivation with mental imbecility, and does not seem to know the difference. He also confounds a bigh state of healthy nervous sensibility, with a state of morbid irritability; and again he confounds the "Graham system" with an ex- 
tremely abstemious diet; and out of these errors grow much of his false reasoning. "The brain and nervous system," he asserts, "are thrown into a state of irritability and excitability, and prepared for the development of disease," by a purely vegetable diet. It is marvellous that a man of common seuse could make such a statement. Nothing is further from the truth. The absence of accustomed stimulus may produce these effects, and so may also extreme and protracted abstemiousness, whether the food be vegetable or animal; but a well-ordered vegetable diet never produces such effects, and it is an amusing fact that the very con trary of what Dr. Lee asserts, has been repeatedly urged by many other physicians against the "Graham system."

That in cases where there has been extreme and protracted abstemiousness, the substitution of a "full diet of vegetable and animal food is sometimes followed by a great abatement of irritability." \&c. I have no manner of doubt; but what does this prove against the "Graham systein ?" or in favor of Dr. Lee's flesh and wine theory?

The whole tissue of Dr. Lee's reasoning is unfair, loose and incoherent-consisting of very limited and imperfectly established premises, and general inferences extorted from them. He has not established a single proposition, nor ascertained a single fact, which goes unequivocally to prove any error in the "Graham system," and yot he has written an article which, with the prejudiced, who wish to believe it true, passes currently for the genuine coinage of truth.

It is surprising loow industriously the Medical and Surgical Journal containing that article, has been circulated in Boston, and the surrounding villages, and with what speed the general charge of Dr. Lee against the "Graham system" has travelled over the United States. Never did a hungry shark catch at the offals which are thrown overboard from a ship, with more greediness, than all classes of society have seized and swallowed this precious morceau from Dr. Lee. It has been about as popular and acceptable as Dr. De Kay's brandy and wine prescription for the cholera.

I have not taken notice of all Dr. I eee's assertions, because I could not do. so without occupying more of your Journal than is convenient for you to allow-and more of my time than I can conveniently spare. I have carefully endeavored to avoid everything like personal severity or disrespect towards Dr. Lee. If any of my language is harsh, it is because Dr. Lee has forced me to use it, and not because I feel unkindly towards him, or disposed to treat him with severity. I cannot but believe that if Dr. Lee had been acquainted with me and the principles which I really do teach, he would never have written the article which I have now hastily replied to. Indeed, he has bad the magnanimity to confess to me that he wrote it under the excitement of awakened sympathies; and that on reviewing it since its publication, be perceived that he had been too unguarded and too sweeping in his statements, and too severe in his personal reflections. But he declares-and I believe him-that in writing that article, he was governed by the information he had received and by the convictions of his own mind. I believe that he intended to do right-or, in other words, that the motive which he held up 
to his own mind, was what he sincerely considered good;-but it is now very certain that he labored under much prejudice, and that he was greatly inisinformed. Yet I can fully appreciate the humane feelings which prompted bim to expose the errors of a system that he sincerely believed to be dangerous to the human family.

Boston, May 10, 1836.

BOSTON MEDICAL AND SURGICAL JOURNAL.

B O S T ON, J U N E 22, 1836.

\section{MAGNETICAL EXPERIMENTS.*}

Our friend Poyen is indefatigable in the pursuit of knowledge. $\mathrm{He}$ gathers something from all the cardinal points, favorable to his own views, which he is determined shall be equally well known to others, by writing most industriously, and, in our humble opinion, far better than those to whom he appears to look with gratification for crumbs.

This little modest duodecimo-embracing the celebrated report of $\mathbf{M}$. Husson to the Royal Academy of Medicine, of Paris-wruld have been a spare-diet essay, if deprived of the ingenious, argumentative introduction of the translator. We were always well entertained at M. Poyen's lectures, because they embraced such a variety of extraordinary facts, appropriately arranged, and our pleasure has not been diminished by reading his seventy-one prefatory pages to the report. Both articles disappointed us:- the first, by Mr. Poyen, on account of its boldness, its logical deductions, and its philosophical character. The other, the heart of the book, fell below our expectations, from the circumstance of its containing just nothing at all. Every atternpt to produce something surprising, fails, because the evidence is not sufficiently definite.

So little is known in this country of animal magnetism, that it will require considerable time to put the right class of observers on the track. The circulation of this translation will doubtless have the effect of directing those, who appreciate the value of transatlantic discoveries in this unexplored domain, to the observance of phenomena which would otherwise have escaped their notice. We are inclined to believe that no great advances will be made in it here: we have not the requisite ardor. Were it not so, the recent experiments in Boston would have produced a stronger sensation in the minds of medical men. However, without dwelling on this point, it is susceptible of demonstration that the Report, together with its accompaniments, throws all the light there is to be had on the unaccountable doctrine of Animal Magnetism.

\section{MASSACHUSE'TTS MEDICAL SOCIETY.}

THE following are the officers of the Society for the current year :George C. Shattuck, M:D. President.

Nathaniel Miller, M.D. Vice President.

\footnotetext{
- Report on the Magnetical Experiments tnade by the Commission of the Royal Academy of Medicine of Paris, read in the meeting of June 20,1831 , by M. Husson, the reporter. Translated from the
French, and preceded with an introduction, by CHARLEI Porew Br. Buvvar. Boston, publiahed by $\mathbf{D} . \mathbf{K}$. Hitcheock -1836 .
} 